\title{
- A crítica em verso de João Cabral
}

\section{Fernando Fiúza MoreiRa}

Professor Adjunto da Universidade Federal de

Alagoas e doutor em Literatura pela Université

Stendhal Grenoble 3.

Resumo: A crítica literária exercida pelos poetas é uma das marcas mais salientes da poesia moderna. João Cabral de Melo Neto, diferentemente de outros poetas modernos, que escreveram majoritariamente em prosa a crítica literária, exerceu esta, sobretudo, em versos, e em volume suficiente a ponto de ter organizado uma antologia composta apenas de poemas críticos. Tenta-se aqui rastrear as principais correntes críticas que servem de suporte a seus poemas.

Palavras-chave: João Cabral de Melo Neto; poesia; crítica literária.
Abstract: Literary criticism by poets is one of the main characteristics of modern poetry. Unlike other modern poets, who wrote literary criticism essentially in prose, João Cabral de Melo Neto did it mostly in verse, sufficiently to organize an anthology of critical poems. The purpose of this paper is to trace the principal theoretical foundations that supported such poems.

Key words: João Cabral de Melo Neto; poetry; literary criticism. 

Quem se interessa por João Cabral de Melo Neto observa sem dificuldade a presença da palavra "crítica", tanto em sua obra (poesia e ensaios), quanto nas inúmeras entrevistas e depoimentos que concedeu. Mesmo quando já havia parado de escrever, depois de ter perdido a visão (“Como imaginar Picasso cego?”), no começo da década de 90, continuou, quando falava, a abordar o assunto. Veja-se o que diz na longa entrevista dada ao número 1 dos Cadernos de literatura brasileira (1996), justamente a ele dedicado:

[..] a teoria da literatura sempre me impressionou mais do que a literatura propriamente dita. Mallarmé, por exemplo, me atrai mais como teórico do que como poeta. Quanto a mim, ocorreu o seguinte: na juventude, eu frequentava um grupo de intelectuais no Recife, que se reunia no Café Lafayette, e tinha a ambição de ser crítico literário. Mas descobri que não possuía cultura suficiente para isso. Para poder continuar a frequentar o grupo, passei a escrever poesia. Mas tentei fazer poesia crítica: de autores, de realidades. Outro fator que me afastou da possibilidade de ser crítico literário é que saí do Brasil aos 27 anos e acompanhava mal a produção literária daqui. Também nenhum jornal me convidou para escrever resenhas, de modo que desisti deste projeto.

Cabral faleceria três anos depois desta e de outras respostas dadas a questões formuladas não só pela editoria dos Cadernos, como por professores críticos (João Alexandre Barbosa, Luiz Costa Lima, Benedito Nunes e Alfredo Bosi). Essa entrevista serve, portanto, de síntese do que afirmara anteriormente sobre o tema; basta conferir o que se encontra no item "Crítica" (p. 24 a 26) do livro Ideias fixas de João Cabral de Melo Neto (1998), inventário organizado por Félix de Athayde, do que disse o poeta a várias fontes sobre os mais variados assuntos. 
O autor chegou mesmo a organizar uma antologia, cujo título é Poesia crítica, em 1982, em que se encontram presentes poemas de toda sua obra até a recolha Escola das facas, lançada em 1980. Quando em seguida publica Agrestes (1985), põe o título de uma das partes de "Linguagens alheias", espécie de continuação da antologia. Este será, portanto, nosso corpus e, apertando mais o recorte, por motivo de espaço, utilizaremos apenas o que o autor escreveu sobre outros escritores. $\mathrm{O}$ que nos interessará nesse conjunto de poemas será detectar de que suportes críticos o poeta lança mão para exercer o ofício a que se achava predestinado, mas que teve de abrir mão, em parte. Antes da análise e interpretação dos poemas mais significativos, faz-se mister, no entanto, uma breve abordagem da forma e da história da relação dos poetas com o ato crítico.

Benedito Nunes (2000, p. 51) descarta a cogitação de que a crítica literária "é da idade de Platão" ou de Aristóteles, e localiza no século XVIII seu começo:

[...] quando, arruinados os cânones do classicismo e com a pública difusão iluminista do livro na sociedade burguesa, às vésperas do romantismo, [o crítico] passou a cumprir, antes de tudo, aquela primeira obrigação de ler literatura, que Northrop Frye em nossos dias lhe cobrou como seu estrito dever para com o esclarecimento de outros leitores das mesmas obras sobre as quais formula antecipadamente apreciações ou juízos, seja avaliando-as, interpretando-as e descrevendo-as.

Quando se delineia nitidamente o romantismo entre os povos protestantes (Alemanha e Inglaterra), vê-se surgir este ser híbrido do poeta-crítico (ou poeta-filósofo), que depois seria assimilado cultural e socialmente, perdendo, felizmente, a nefasta etiqueta da "hibridez". Desde Schiller, os irmãos Schlegel, Goethe, Novalis, Coleridge, tem-se uma produção consistente por parte dos poetas de textos críticos, incrementada na França a partir de Baudelaire e, em seguida, de Mallarmé; no século 
XX, Valéry, Eliot, Pound, Ungaretti, Octavio Paz, Borges, Haroldo de Campos e outros tornaram-se conhecidos até mais, em certos casos, como críticos do que como poetas, mesmo porque o texto crítico é mais facilmente traduzível do que o poema, sobretudo num século em que a poesia deu, muitas vezes, importância maior ao significante do que ao significado. O que se observa, no entanto, é que na grande maioria das obras desses autores há uma nítida distinção entre o texto crítico em prosa e o poema em verso. É como se os poetas dividissem claramente suas obras em compartimentos estanques: de um lado, a crítica feita em prosa; do outro, a poesia, que pode ser em verso ou não. Que me ocorrem, três poetas misturaram a água e o óleo: Francis Ponge, Murilo Mendes e João Cabral. Mas foi este quem fez a crítica mais sistemática em versos (Ponge escreveu sua poesia em prosa e Murilo Mendes, sua parte crítica, também, como nos Retratos-Relâmpago).

Ora, escrever crítica em verso é um duplo estranhamento, tanto para o escritor, que é obrigado à coerção versificatória (ritmo, metro, rima, estrofe, elipse, imagens etc.), quanto para o leitor de poesia, que tem como horizonte de expectativa temas como os sentimentos, os estados d'alma, até os objetos e coisas do cotidiano, além da metapoesia (estes últimos, temas da poesia do século $\mathrm{XX}$ ), mas não é evidente a poesia sobre outros escritores, menos ainda quando essa poesia não seja uma celebração, uma "ode", mas sim uma crítica no sentido de que esta tem como função "escolher, interpretar, analisar e, finalmente, julgar” (WELLEK, p. 16-17).

Poesia crítica, única antologia feita por Cabral de sua obra, contém 80 poemas, divididos em duas partes: a primeira, com 21 poemas, intitula-se "Linguagem"; a segunda, "Linguagens", com 59. Na primeira parte, o poeta reuniu os poemas autorreflexivos sobre a poesia; na segunda, aqueles sobre as obras (e vidas) dos outros, e "os outros" não são só poetas e escritores, mas também artistas plásticos, jogadores de futebol, cantores e toureiros, ou seja, outras linguagens que não a escrita. Além da autorreflexão e da reflexão sobre a "poiésis" inerente a 
cada ofício, seja ele artístico ou esportivo, um aspecto unifica a antologia: em cada "criticado" veem-se, às vezes velada, em outras explicitamente, as linhas de força que regem a poética cabralina, seja por identificação, seja por oposição. Desta última postura, mais rara, diga-se, tomese como exemplo "Anti-Char” (p. 64):

Poesia intransitiva, sem mira ou pontaria: sua luta com a língua acaba dizendo que a língua diz nada.

É uma luta fantasma, vazia, contra o nada; não diz a coisa, diz vazio nem diz coisas, é balbucio.

Em apenas oito versos (os dois primeiros de cada estrofe, hexassílabos, os dois últimos, octossílabos, rimados entre si, arranjo típico de Cabral: os metros pares e as rimas toantes), o autor não só se posiciona contra ("anti") René Char, mas reitera um dos valores caros à sua poética: a transitividade, ou seja, a poesia deve ser sobre alguma coisa e não enveredar por especulações filosofantes. De fato, Char foi um poeta muito próximo a Martin Heidegger, que o elegeu, na França, como seu principal interlocutor entre os poetas. $\mathrm{Na}$ entrevista aos Cadernos (p. 20), Benedito Nunes, declarando que gosta da poesia de Char e da do entrevistado, pergunta se este poema é "simples aversão pessoal, no polo oposto de suas afinidades literárias, ou juízo crítico de exclusão?” Cabral, ao responder, elimina a alternativa "aversão pessoal" e justifica seu "juízo crítico": "Apenas Char significa para mim o pós-surrealismo e eu não tenho interesse por ele. Ele foi um herói da resistência contra os alemães e daí veio uma grande reputação. Acho, por exemplo, muito mais interessante o Henri Michaux." (p. 21). O cotejamento entre o poema e a resposta à pergunta faz-nos concluir pela superioridade da escrita em relação à fala. No poema, a crítica é feita à linguagem e à temática de Char, 
portanto, uma crítica que se detém no texto, como ocorre no Formalismo Russo, no New Criticism anglo-saxão, ou no Neoaristotelismo da Escola de Chicago. Na entrevista, Cabral parte para uma justificativa extraliterária e atribui a fama de Char a motivações políticas. Fiquemos com o poeta crítico, pois neste curto poema faz, de maneira precisa e rica, descrição, interpretação e julgamento da obra, e que nada deve aos mais extensos textos em prosa.

Se "Anti-Char" incide sobre o texto em si, sem derivações biográficas, isto não acontece, por exemplo, em "Retrato de poeta" (p. 53), onde vida e obra são sacadas para julgar um antípoda não nomeado:

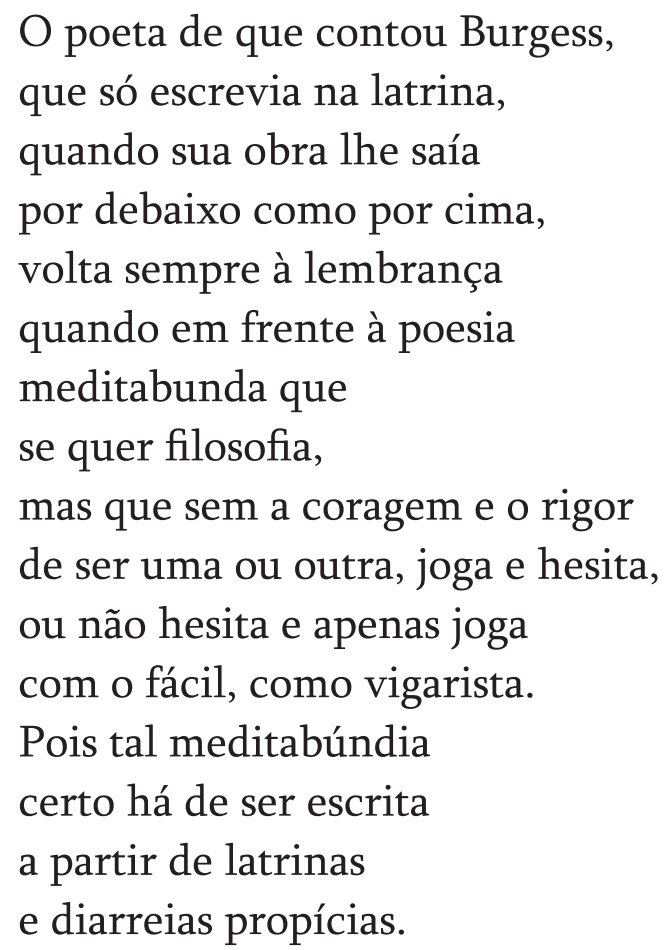

Num poema formalmente atípico (versos que vão de 6 a 9 sílabas e ausência de estrofes), Cabral imbrica vida e obra, a primeira justificando a segunda (ponto de vista à abatre desde o Proust de Contre Sainte-Beuve, que em seguida recebeu várias mãos de tinta teórica das correntes formalistas). Mas, se o poeta incorre nesse "pecado", é para, por negação, mais uma vez reiterar os valores que regem sua poética: a poesia como um ofício sério e cerebral, pensada, refletida, escrita em mesa (e não "na latrina"), com duras coerções que contenham o derramamento, $o$ 
fácil (as “diarreias propícias”). No entanto, "une certaine liberté de ton et de plume" (THUMEREL, 2002, p. 22) de valer-se dos vários princípios críticos, formulados desde o século XIX, é uma característica da crítica dos escritores, ainda mais quando esta se faz em versos, pois que a poesia, sobretudo a moderna, é domínio exclusivo do autor, que cria suas próprias regras, funda sua poética, não as herda do passado.

Ainda na clave sainte-beuviana, só que à maneira do que se chama hoje "politicamente incorreto" pelos Estudos Culturais (é cômico imaginar um bando eletrizado de ativistas gays, insuflados por adeptos da Queer Theory, protestando na porta da casa do poeta), é "Caricatura de Henry James", de Agrestes (p. 77). "Caricatura", evidentemente, mitiga a virulência bem-humorada do poema e serviria de contra-argumento à imaginada estrepitosa reação:

O romancista solteirona

pergunta a uma outra matrona:

como comportar-se na mesa, como comportar-se na igreja,

como comportar-se na estreita, e de mil tons, moral inglesa,

ele, bem-criada nova-iorquina a quem o que é América irrita.

$[\ldots]$

O primeiro verso, ao fazer concordar um substantivo masculino ("o romancista") com um adjetivo feminino ("solteirona"), num desvio da norma, algo recorrente em Cabral (o que o faz um adepto do preceito judicativo dos formalistas russos de que a arte deve violentar a norma para causar o estranhamento), já instala a ironia, que será a figura dominante de todo o poema. A mesma discordância entre os gêneros está presente ainda no sétimo verso: "ele, bem criada nova-iorquina". 
Os outros versos do trecho citado (primeira metade do poema) agregariam, à fictícia manifestação de protesto, as feministas, pois aquilo que Henry James quer saber de uma matrona são atitudes que, sob uma visão senhorial, seriam mais apropriadas ao sexo feminino: "comportar-se na mesa", "na igreja", "na estreita [...] moral inglesa".

Há ainda outros poemas em que Cabral destila sua antipatia por aspectos da vida do escritor que lhe serve de tema, sem nem ao menos referir-se à obra, como é o caso de "A Camilo Castelo Branco" (p. 76 de Agrestes) e "Exceção Bernanos, que se dizia escritor de sala de jantar" (de Poesia crítica, p. 73). Mas há também simpatia, e dentro desta encontra-se um ato de vida que reverbera em caros valores de sua poética. Caso exemplar é "O silêncio de Racine" (p. 68 de P.C.):

\author{
Duro, o mais duro, o jansenista, \\ o sempre cada vez mais difícil, \\ como obtê-lo senão \\ por algum artifício? \\ Mas um artifício não estará \\ mais para o fácil que o difícil? \\ Então calar: usar \\ um silêncio artifício.
}

À primeira leitura, o poema acima se refere ao fato de aos 47 anos o poeta dramático Jean Racine ter deixado de escrever, depois de receber do rei de França uma confortável sinecura. Mas Cabral se serve do episódio para atribuir valor negativo ao artifício, aqui sinônimo de acomodação, de fôrma, e realçar positivamente o silêncio, sinônimo da negação, do "não", tão caro à poesia moderna. O não escrever, o saber silenciar, é tão ou mais importante do que continuar escrevendo, quando o continuar significa repetição.

Se a vida explicar a obra é um clichê saintebeuviano, a morte ser coerente com a obra é sua dupla inversão. E Cabral se vale dessa visada em três poemas da antologia: "Na morte de Marques Rebelo" (p. 52), "W.H. Auden" (p. 57) e "O espelho partido" (p. 66), este também 
sobre Marques Rebelo; em Agrestes, a morte do poeta inglês é revisitada (p. 87). Fique-se com o primeiro dos quatro poemas:

Morreu sem deixar a gramática

de sua maneira clínica:

essa maneira de médico

que toma a doença com pinças,

e seja doença de fora

seja de dentro, examina-a

limpamente, do mais alto,

da ciência, do fora, do cima.

Daquele cima que permite

ser/fazer com assepsia:

sem beatice, se a ternura,

e desamargo, se a ironia.

O poeta crítico aqui atribui à morte as virtudes da obra do morto, que, por sua vez, são virtudes da obra do poeta, num jogo especular recorrente, como já foi dito páginas atrás. $\mathrm{O}$ "ser/fazer com assepsia”, do antepenúltimo verso, vale tanto para a obra de Marques Rebelo quanto para a de João Cabral: a assepsia do vento do mar, por exemplo, em "Cemitério alagoano", de Quaderna, é um poema que pode ser lido como uma declaração de princípios de toda a poética cabralina.

Se recorrer à vida para explicar a obra, ou recorrer a esta para explicar a morte, traz um ranço do biografismo que infestou a crítica ocidental durante décadas (e ainda não foi totalmente eliminado), não se pode negar, mesmo com toda a carga contrária feita pela crítica imanente (que chegou à morte do autor, decretada por Barthes), que esse vínculo vida-obra-morte é extremamente atraente até ao mais asséptico dos críticos, mesmo que, ao operar a crítica, tais dados sejam omitidos. A curiosidade pela vida dos outros é uma constante antropológica, assim como a poesia e o conto.

Mas Cabral soube fazer essa crítica mais asséptica, em que a vida do autor criticado é deixada à parte, e em que só o texto é levado em conta. Os exemplos são 
vários, e serão trazidos aqui aqueles mais bem-sucedidos e representativos de certas vertentes críticas do século XX.

A classificação é um dos atributos da teoria. Aglutinar seres e objetos por afinidades entre eles e em oposição a outros é uma operação redutora, no entanto necessária à apreensão da realidade. A teoria e a crítica literárias se valem legitimamente da classificação para fins didáticos. Cabral não se furtou a esse procedimento. Em Poesia crítica há três poemas "classificatórios": "Pescadores pernambucanos" (p. 16), "Retrato de escritor" (p. 75) e "Generaciones y semblanzas (fragmento)" (p. 79). Em nenhum deles há nomes citados; são, portanto, poemas antes teóricos do que críticos. No primeiro, o poeta servese da imagem de quatro tipos de pescadores para classificar, metaforicamente, os poetas: o de vara, o de jereré, o de tarrafa e o de covo. Só o de jereré tem atributos positivos, que se confundem com as qualidades poéticas prezadas por Cabral; os outros três são seus anversos. No segundo poema, também prenhe de imagens, os tipos são reduzidos a dois: insolúvel e solúvel. É fácil perceber que o polo em que se posiciona a obra do classificador é a do insolúvel. No terceiro, primeira das quatro partes que originalmente constam de Serial (1961), a classificação é também bipolar: de um lado aquele que "[...] procura / viver fora de portas", do outro, "[...] o poeta-hortelão / que se tranca na horta" para produzir seus poemas metaforizados em "os tomates sensíveis, / as alfaces barrocas, / couves meditabundas, / sentimentais cenouras"; todos os quatro adjetivos são pejorativos no vocabulário de Cabral. Por inferência, portanto, o poeta-hortelão seria o oposto do poeta crítico.

A atenção voltada estritamente à linguagem dos autores criticados (e nomeados, não raro desde o título) será encontrada na maioria dos poemas, tanto de Poesia crítica, quanto nas "Linguagens alheias" de Agrestes. Estes fazem de Cabral um crítico em sintonia com as correntes da crítica imanente, suas contemporâneas. Um exemplo da crítica descritiva, que tem por base a Poética de Aristóteles e desemboca no Estruturalismo, é "Denton Welch" (Agrestes, p. 88): 
Escrever na prosa qualquer, sem truques, bossas, sem sequer.

Porém tão de novo escrevia a coisa gasta que ele via,

que estava nítida em si mesma, ou noutra, virgem, atmosfera.

Cada coisa de que escrevia criada no instante parecia,

e porque recente e tão viva, coisa que chega de mãos limpas,

impressa no instante preciso do pão fresco daquele livro.

A um livro chamou Maiden Voyage, em português, primeira viagem,

que é a peripécia de falar, em língua virgem, no inglês que há.

Em 16 octossílabos, divididos em oito dísticos com rimas toantes e emparelhadas, Cabral atém-se à linguagem do pintor e escritor inglês Maurice Denton Welch, nascido em Xangai (1915) e morto cedo (1948), mais precisamente à linguagem de seu livro de estreia e o mais conhecido, Maiden voyage, autobiografia ficcional. A prosa despojada de Welch, com que pintou retratos perspicazes de pessoas, objetos, lugares e acontecimentos, é posta em destaque nos dois primeiros versos. No entanto, o despojamento não é sinônimo de recorrência a lugares-comuns, pelo contrário: "Porém tão de novo escrevia / a coisa gasta que ele via". A grande virtude de Welch seria, portanto, apresentar a realidade com feições inéditas, ainda que em "prosa qualquer". Sua pintura é uma tradução intersemiótica de sua escrita, pois que pintou a realidade (foi um 
figurativo) com traços nítidos, mas com elementos fantásticos, o que o leva a reconfigurá-la. A tensão responsável pela alta voltagem estilística de sua obra é detectada de forma precisa por Cabral na última estrofe: “[...] a peripécia de falar, / em língua virgem, no inglês que há." Como reinventar a língua, usando a língua que há? Só através do engenho. E é "engenho" (a "poiésis") a palavra-chave de outro poema em que os aspectos formais são os únicos destacados: “A Quevedo" (p. 62 de Poesia crítica):

Hoje que o engenho não tem praça, que a poesia se quer mais que arte, e se denega a parte do engenho em sua traça,

nos mostra teu travejamento que é possível abolir o lance, o que é acaso, chance, mais: que o fazer é engenho.

O poeta barroco espanhol Francisco Quevedo (1580-1645) é invocado como paradigma e interlocutor (numa mirada sincrônica tão cara ao Estruturalismo) para se contrapor à poesia espontânea (sem travejamento). Note-se no primeiro verso a ambiguidade da palavra "engenho", que, à primeira leitura, nos traz a fábrica de açúcar assim nomeada no Brasil, de seus primórdios ao começo do século $\mathrm{XX}$, quando foi superado e destruído pela usina, numa brutal concentração de renda, de que a família do poeta pernambucano sofreu as consequências. Mas, a partir do segundo verso, esse sentido é narcotizado, e ganha a frente semântica o "engenho e arte" camonianos (último verso da segunda estrofe de Os lusíadas). Também se observa, na segunda estrofe, uma menção ao princípio mallarmaico da literatura como arma contra o acaso, e foi Mallarmé quem anunciou a reativação de Gôngora e de outros poetas barrocos, o que de fato só veio a ocorrer pelas mãos da Geração de 27 na Espanha, sobretudo pelos 
ensaios que Lorca dedicou a Don Luís. Cabral sempre se alinhou formalmente com essa geração (leitora de Mallarmé), a ponto de pôr como epígrafe um verso de um de seus próceres, Jorge Guillen, em Psicologia da composição (1947). O poema acima transcrito não toca nem nos temas, muito menos na vida de Quevedo, só no princípio formal que rege sua poética: o travejamento. Numa deriva interpretativa, pode-se ler "travejamento" também como aquele das coroas dentadas que movem a moenda, transmitindo-lhe pela tração a energia que vinha do negro, da água, da besta e, já mais tarde, do vapor. Caberia ainda lembrar o acaso histórico: Quevedo viveu quase toda sua vida enquanto o Brasil pertenceu à Espanha (1580-1640), no auge do preço do açúcar, o que suscitou as invasões holandesas.

Mas é em "Graciliano Ramos" (p. 81-82 de Poesia crítica) que Cabral chega à excelência da crítica em verso: pela clareza expositiva (o que deveria ser o dever de toda crítica, visto que uma de suas funções é traduzir em linguagem didática e conceitual as possibilidades semânticas da linguagem artística); pelo engenhoso emprego da imagem em função do esclarecimento; pela capacidade de síntese, pois dá conta das linhas mestras de toda uma obra em apenas 32 versos; pela intimidade esmiuçante que tem com a obra em questão; pelo recurso (empregado em outros poemas) de o eu lírico (ou ficcional) ser o do criticado (quem fala é Graciliano). Nesse poema, Cabral sintetiza as grandes correntes críticas do século $\mathrm{XX}$, inclusive a lukácsiana, numa demonstração de liberdade que todo grande crítico tem ao abolir os preconceitos e disputas entre as correntes, motivo de gasto de tempo com o extraliterário e de empobrecimento analítico-judicativo.

Falo somente com o que falo: com as mesmas vinte palavras girando ao redor do sol que as limpa do que não é faca: 
de toda uma crosta viscosa, resto de janta abaianada, que fica na lâmina e cega seu gosto de cicatriz clara.

Falo somente do que falo: do seco e de suas paisagens, Nordestes, debaixo de um sol ali do mais quente vinagre:

que reduz tudo ao espinhaço, cresta o simplesmente folhagem, folha prolixa, folharada, onde possa esconder-se a fraude.

Falo somente por quem falo: por quem existe nesses climas condicionados pelo sol, pelo gavião e outras rapinas:

e onde estão os solos inertes de tantas condições caatinga em que só cabe cultivar o que é sinônimo de míngua.

Falo somente para quem falo: que padece sono de morto e precisa um despertador acre, como o sol sobre o olho:

que é quando o sol é estridente, a contrapelo, imperioso, e bate nas pálpebras como se bate numa porta a socos. 
Em seus preferidos octossílabos, distribuídos em quartetos, com rimas toantes entre o segundo e o quarto versos, Cabral se vale da regência múltipla do verbo "falar", posto na primeira pessoa do singular em todo primeiro verso das estrofes ímpares, para ordenar o poema e a crítica que este contém. Divide-o em quatro blocos separados por asteriscos, cada bloco composto de duas estrofes, em que a segunda é o desdobramento da primeira, indicado pelo emprego dos dois-pontos ao término dos quartos versos dos conjuntos estróficos, num paralelismo sintático exemplar. Cada bloco trata de um fator inerente à atividade literária: no primeiro, da linguagem; no segundo, do tema (e a paisagem como tema determinante em Graciliano); no terceiro, de a quem o autor dá voz, quem representa (os personagens da obra); e no quarto, do público a quem se dirige. Descrito assim, o poema pareceria um plano de aula, ou um texto crítico que caísse num pobre didatismo. Mas não é isso o que se vê, pois as imagens, a visibilidade, seu lado concreto, palpável, dão ao poema crítico uma alta voltagem poética. Essas imagens (metáforas e símiles), colhidas no universo comum aos dois (crítico e criticado), ao mesmo tempo que iluminam a obra abordada, informam sobre os valores que regem não só a crítica que está sendo operada, mas também sobre a poética do poeta crítico. Daí infere-se que os princípios que regem a poética cabralina são semelhantes aos que regem sua crítica. $\mathrm{O}$ artifício de empregar o eu lírico de Graciliano só deixa mais evidente a fusão entre crítica e poética: é Graciliano quem se descreve, e é Cabral também.

Pelo campo semântico dominante (o do sertão, da secura, da privação, em que o único excesso que há é o da luz, excesso que ganha valor positivo pelo que tem de agente de assepsia), Cabral realça o Graciliano sertanejo, aquele de Vidas secas e de parte de Infância. É bem sabido que o escritor alagoano ambientou cada um de seus quatro romances em uma região climática: Caetés, no agreste (Palmeira dos Índios); São Bernardo, na zona da mata (Viçosa); Angústia, no litoral (Maceió); e Vidas secas no 
sertão. E é este último, portanto, o espaço privilegiado no poema. Mas a linguagem do romancista e memorialista, se é comentada por imagens tiradas do espaço sertão, tem, em qualquer que seja o livro, uma unidade estilística a precisão, a economia, a ausência de adornos e gordura ("resto de janta abaianada") — que faz de Graciliano o modelo da prosa moderna em língua portuguesa, a impregnar virtuosamente não só o discurso ficcional, mas também o jornalístico e dissertativo. Ao eliminar as cabriolas machadianas, os excessos coelho-netais, o torneio frásico arcaizante do Lobato para adultos, ele aproximou a língua escrita da língua falada (um dos cavalos de batalha do modernismo), mas sem a afetação de mimetizar os erros recorrentes na fala (como fez Guimarães Rosa, por exemplo). Para Cabral, Graciliano "fala" (aqui no sentido da "parole" saussuriana, da língua em ação), mas sua "fala" é antes um arquétipo, ou esqueleto, ou o que deveria ser: uma matriz da sanidade verbal.

No último bloco estrófico, que trata do leitor (Cabral se adiantou à Estética da Recepção), vê-se claramente um princípio do Formalismo Russo: a arte como um fenômeno capaz de modificar a percepção do mundo em quem a frui, de reconfigurá-lo (é uma pena que a crítica marxista não tenha levado em conta tal aspecto). A prosa de Graciliano é dirigida a "quem padece sono de morto", pois é "um despertador / acre", que se transforma pelo símile em "sol estridente", "a contrapelo". Só uma linguagem violenta de luz, que "bate nas pálpebras como / se bate numa porta a socos", seria capaz de acordar o leitor, de inquietá-lo, de mudar-lhe a percepção do mundo, de chamar sua atenção para as mazelas seculares de um país injusto, desequilibrado. De nada adiantaria fazer tais denúncias se a linguagem empregada não fosse violenta e solar, pois que seria cúmplice da classe dominante, que pela "cordialidade" e pela falta de clareza verbal (a retórica, a lábia, o "vem cá, meu bem") se perpetua e a um Estado por ela manipulado.

Do outro lado de "Graciliano Ramos", mas dotado de grande acuidade para alcançar em poucos versos o cerne 
estilístico da obra criticada, encontra-se "Casa-grande \& senzala, quarenta anos" (Poesia crítica, p. 60). Em apenas seis versos, Cabral dá conta da fusão operada por Gilberto Freyre, em seu livro mais célebre, entre o tema tratado e o estilo linguístico adotado para tratar esse tema. Convém ainda ressaltar a antítese: para abordar uma obra que tem como valor a secura, a economia de meios, 32 versos; para uma que tem a elasticidade, a exuberância verbal, apenas seis versos:

Ninguém escreveu em português no brasileiro de sua língua: esse à vontade que é o da rede, dos alpendres, da alma mestiça, medindo sua prosa de sesta, ou prosa de quem se espreguiça.

Se Cabral e Graciliano se encontravam no lado oposto ao de Gilberto Freyre no espectro políticoideológico brasileiro, nem por isso o poeta crítico deixou de valorar positivamente a forma com que trata a língua, sua capacidade de dar-lhe um selo de brasilidade, de livrála dos torneios lusitanizantes.

Atualizado com as correntes críticas que iam surgindo durante sua carreira literária, Cabral lança mão da crítica genética em "Debruçado sobre os cadernos de Paul Valéry” (Agrestes, p. 94-95). O acesso às notas prévias (os Cahiers) aos escritos do autor de "Le cimetière marin" faz Cabral expor uma evidência: "o fazer é sujo". Trata-se aqui da longa batalha que começa na "ideia" e vai até o "imprima-se", de resto inerente a qualquer ofício artístico. A vista sobre o laboratório literário de um poeta frequentado desde a juventude renova a admiração que tinha quando só o conhecia pelo impecável acabamento formal. Ao "debruçar-se" sobre os esboços, as tentativas, os acertos e fracassos, o trabalho duro para alcançar o "perfeito cristal", o poeta pernambucano saúda Valéry pela "coragem de se ter visto", e de exibir-se, ele, que foi tão avesso a tal atitude. O espetáculo sujo do fazer ganha a frente valorativa da privacidade. Nesse poema, observa-se também o freio de 
mão que Cabral puxa diante dos excessos do Estruturalismo semiológico, quando este decreta a morte do autor e delega à linguagem total autonomia, como se fosse esta que conduzisse o sujeito, e não o contrário: "nesse momento em que só poucos / são capazes de ver-se, loucos // de tudo o que pode a linguagem".

Ainda a contrapelo do Estruturalismo, que além de tentar abolir o autor, tentou abolir o referente (o espaço), há em Agrestes (p. 91) "A literatura como turismo":

Certos autores são capazes

de criar o espaço onde se pode

habitar muitas horas boas:

um espaço-tempo, como o bosque.

Onde se ir nos fins de semana,

de férias, até aposentar-se:

de tudo há nas casas de campo

de Camilo, Zé Lins, Proust, Hardy:

A linha entre ler conviver

se dissolve como em milagre;

não nos dão seus municípios

mas outra nacionalidade,

até o ponto em que ler ser lido

é já impossível de mapear-se:

se lê ou se habita Alberti?

se habita ou se soletra Cádis?

Em seus célebres octossílabos, rimados toantemente o segundo e o quarto versos das quatro estrofes, quatro romancistas de três línguas diferentes (português, francês e inglês) são convocados para ilustrar o princípio da equivalência entre ler e habitar. A capacidade dos romancistas de seduzir o leitor, com a construção do espaço, é tamanha que este, medusado, perde o discernimento que separa o ato de ler daquele de habitar, e essa perda, ou fusão entre os termos, é assinalada pelo significante: "a linha entre ler conviver", quando a norma padrão exige a conjunção aditiva "e" ligando os verbos. Mesmo procedimento utilizado, em 
posição paralelística, se acha no primeiro verso da estrofe seguinte: "até o ponto em que ler ser lido". Mas, assim como se habita um livro, se soletra uma cidade, como consta nos dois últimos versos, em que a equivalência entre ler e habitar é reiterada: ler tem atributos espaciais, e habitar, atributos de ler. Seria uma deriva excessiva encontrar nesse princípio cabralino o eco da proposição de Heidegger de que "a língua é a morada do Ser"?

Se toda crítica é um risco (quem julga será, por sua vez, julgado), fazer uma leitura crítica da obra de João Cabral é mais arriscado ainda, por um motivo bem evidente: sua obra se autoexplica, deixando pouco ao exegeta. O gosto pela teoria e a vocação para crítico, num século em que a poesia experimentou todos os temas e formas possíveis, no mesmo século $(\mathrm{XX})$ em que a crítica atinge seu auge, deram a Cabral a oportunidade de direcionar parte de sua poética para a descrição, a análise e o julgamento de obras e autores. E isso só foi possível pela junção da inclinação pessoal com o momento histórico. Nascesse no século XIX, seria obrigado a escrever sua crítica apenas em prosa, deixando o verso para os temas "poéticos". Não é mera coincidência histórica o fato de sua obra ser contemporânea (da década de 40 à década de 80) da fase mais fértil da crítica literária ocidental. Cabral usou a liberdade temático-formal, característica da época em que escreveu, e a quase obrigação por parte do artista moderno de ser dotado de pensamento crítico, para escrever sua crítica em verso. E nela se pode encontrar uma segunda dobra da liberdade: a de empregar, sem preconceito, princípios de todas as grandes correntes críticas: do Biografismo de Sainte-Beuve ao PósEstruturalismo. Esse à vontade entre o cipoal de categorias e conceitos junto à excelência de sua poesia dá à Cabral um lugar de destaque na crítica literária brasileira. E tal destaque não se deve ao "exotismo" de escrever crítica em verso (quando sua morada é a prosa dissertativa), mas pelo fato de seus poemas críticos cumprirem com o dever principal da crítica: iluminar a obra em questão, dar ao leitor novas visadas, novas possibilidades de sentido. 


\section{Referências}

ATHAYDE, Félix de. Idéias fixas de João Cabral de Melo Neto. Rio de Janeiro: Nova Fronteira, 1998.

CABRAL DE MELO NETO, João. Poesia crítica (antologia).

Rio de Janeiro: José Olympio, 1982.

CABRAL DE MELO NETO, João. Agrestes. 2. ed. Rio de Janeiro: Nova Fronteira, 1985.

CABRAL DE MELO NETO, João. Obra completa. Rio de Janeiro: Nova Aguilar, 1994.

CAMÕES, Luís de. Os lusíadas. São Paulo: Cultrix/MEC, 1980.

FRANCESCHI, Antonio Fernando de (Dir. editorial).

Cadernos de literatura brasileira. São Paulo: Instituto Moreira Salles, no 1, mar. 1996.

NUNES, Benedito. A crítica literária no Brasil, ontem e hoje. In: MARTINS, Maria Helena (Org.). Rumos da crítica. São Paulo: Senac/Itaú Cultural, 2000.

PROUST, Marcel. Contre Sainte-Beuve - notas sobre crítica e literatura. São Paulo: Iluminuras, 1988.

THUMEREL, Fabrice. La critique littéraire. Paris: Armin Colin, 2002.

WELLEK, René. Conceitos de crítica. São Paulo: Cultrix, [197-]. 
